\title{
Bone marrow transplantation versus immunosuppressive therapy in patients with acquired severe aplastic anemia
}

\author{
Andrea Bacigalupo $^{1} \cdot$ Sabrina Giammarco $^{1} \cdot \operatorname{Simona~Sica~}^{1}$
}

Received: 24 April 2016 / Revised: 23 May 2016 / Accepted: 29 May 2016 / Published online: 8 June 2016

(c) The Japanese Society of Hematology 2016

\begin{abstract}
Standard front-line treatment for acquired aplastic anemia (AA) for patients is either immunosuppressive therapy (IST) or bone marrow transplantation (BMT), usually from an HLA identical sibling. Whereas long-term survival is comparable with either treatment, important differences remain: IST patients may have incomplete or no recovery, are exposed to late clonal disorders and relapse of the original disease. Transplantation is a curative treatment, but patients are exposed to transplant-related complications both acute and chronic, such as chronic graft versus host disease (cGvHD). In the year 2000, a study by the European Group for Blood and Marrow Transplantation (EBMT), looked at failure free survival (FFS), in patients receiving first-line BMT from an HLA identical sibling, or the first-line IST. Young patients with low neutrophil counts benefited of the first-line BMT; the opposite was true for older patients with higher neutrophil counts; and a third intermediate group of patients had comparable survival irrespective of the first-line therapy. We have now studied a more recent cohort of patients to assess whether things have changed over the years. We have found similar results, although overall survival has improved, as a consequence of changes in the IST and BMT protocols.
\end{abstract}

Keywords Aplastic anemia - Immunosuppressive therapy · Bone marrow transplantation

Andrea Bacigalupo

Andrea.bacigalupo@unicatt.it

Sabrina Giammarco

Sabrina.giammarco@policlinicogemelli.it

Simona Sica

Simona.sica@unicatt.it

1 Istituto di Ematologia, Universita' Cattolica del Sacro Cuore, Fondazione Policlinico Universitario Gemelli, Largo Agostino Gemelli 1, Rome, Italy

\section{Advances in our understanding of pathophysiology of SAA}

Acquired SAA has been regarded as an immune-mediated destruction of hematopoietic cells, as suggested by in vitro data and by clinical response to immunosuppressive therapies [1]. Recently, other potential mechanism leading to exhaustion of the stem-cell pool has been identified. TERC and TERT mutations, associated with short telomeres, were described in some patients with acquired aplastic anemia, suggesting a wide spectrum of telomeropathies and confirming the association with cytopenia [2, 3]. Interestingly, sex hormones increase telomerase activity and this results in elongated telomeres in vitro [4], and, possibly, in vivo: this may explain the clinical effect of androgen therapy in patients with aplastic anemia [5]. Short telomeres can serve as predictors of response to IST: in 113 children with SAA, short telomeres, and the lack of glycosil-phosphatydilinositol (GPI) negative cells were negative predictors of response to IST and survival [6].

Finally, next-generation sequencing and array-based karyotyping have highlighted a number of somatic mutations in $30 \%$ of SAA patients [7]: these mutations can be then identified as positive or negative predictors of survival, the latter especially if they occur in candidate genes for myelodysplastic syndromes, acute myeloid leukemia, or both.

\section{Advances in immunosuppressive treatment}

ATG + CSA

The standard regimen for the first-line IST remains ATG and CSA, which produces hematological recovery in $50-70 \%$ of cases and excellent long-term survival among 
responders, as shown in several large international studies [8-11]. The survival of patients given a conventional ATG + CSA regimen, has improved over the years, from 57 to $73 \%$ after year 1999 (Fig. 1). The mechanisms by which severe pancytopenia may persist after one or two courses of IST, remain elusive. In some patients, stem-cell numbers may be too low to reconstitute adequate hematopoiesis, even after removal of an acute immune. Other possible explanations for failure to respond to ATG include a non-immune etiology, inadequacy of current immunosuppressive agent, negative regulation of hematopoiesis by stromal elements, or an underlying telomeropathy. Interventions, such as androgens, eltrombopag, and novel immunosuppressants, are being tested.

\section{Eltrombopag}

An oral thrombopoietin mimetic that binds to c-MPL (eltrombopag-EPAG) promotes megakaryocytopoiesis and the release of platelets from mature megakaryocytes. It was initially approved in the US and Europe for treatment of patients with chronic immune thrombocytopenic purpura (ITP). Thrombopoietin (TPO) levels are significantly elevated in patients with SAA, but EPAG may activate different metabolic pathways as compared to TPO: indeed EPAG binds to the membrane-spanning region outside the ligand-binding pocket of c-MPL, and activates JAK-STAT and MAPK pathways.

There are several evidences that EPAG could be effective in the setting of SAA; TPO-receptors, c-MPL, are present on hematopoietic stem cells [12] and TPO has a role in stem-cell survival, self-renewal and expansion, and in regulating quiescent stem cell [13-15]. Congenital Amegakaryocytic thrombocytopenia is caused by bi-allelic mutations in c-MPL, and is characterized by a high risk of developing AA [16]; a homozygous non-sense mutation in $\mathrm{Mpl}$ gene has been reported in association with familial aplastic anemia [17].

Eltrombopag alone, used as a single agent, has produced trilineage hematologic response in $40 \%$ of refractory SAA patients [18]: a long-term follow of 43 patients has confirmed EPAG efficacy in $40 \%$ of patients. Clonal cytogenetic abnormalities developed in 8 out of 44 patients (19\%), among these patients, 6 were non-responding to EPAG and 5 patients developed chromosome 7 abnormalities. If TPO mimetic drug can potentially stimulate clonal expansion is still unclear [19]. Previous in vitro study showed that EPAG can increase megakaryocytic proliferation when added to mononuclear cell from patients with AML and MDS, but in the majority of samples inhibited blast cell proliferation [20]. EPAG has also been used upfront together with the conventional ATG + CSA in 88 patients. There were 3 study cohorts: they all received EPAG at a daily dose of $150 \mathrm{mg}$ from day 14 until 6 months (cohort 1), until 3 months (cohort 2), and in the cohort 3, EPAG was introduced from day 1 . The overall response at 3 and 6 months was 80 and $85 \%$, with CR rates of 28 and $34 \%$, respectively, significantly higher when compared to historical controls $(p<0.001)$, together with faster neutrophil and platelet recovery. Cytogenetic abnormalities and clonal evolution to myelodysplasia occurred at a similar frequency compared to standard IST.
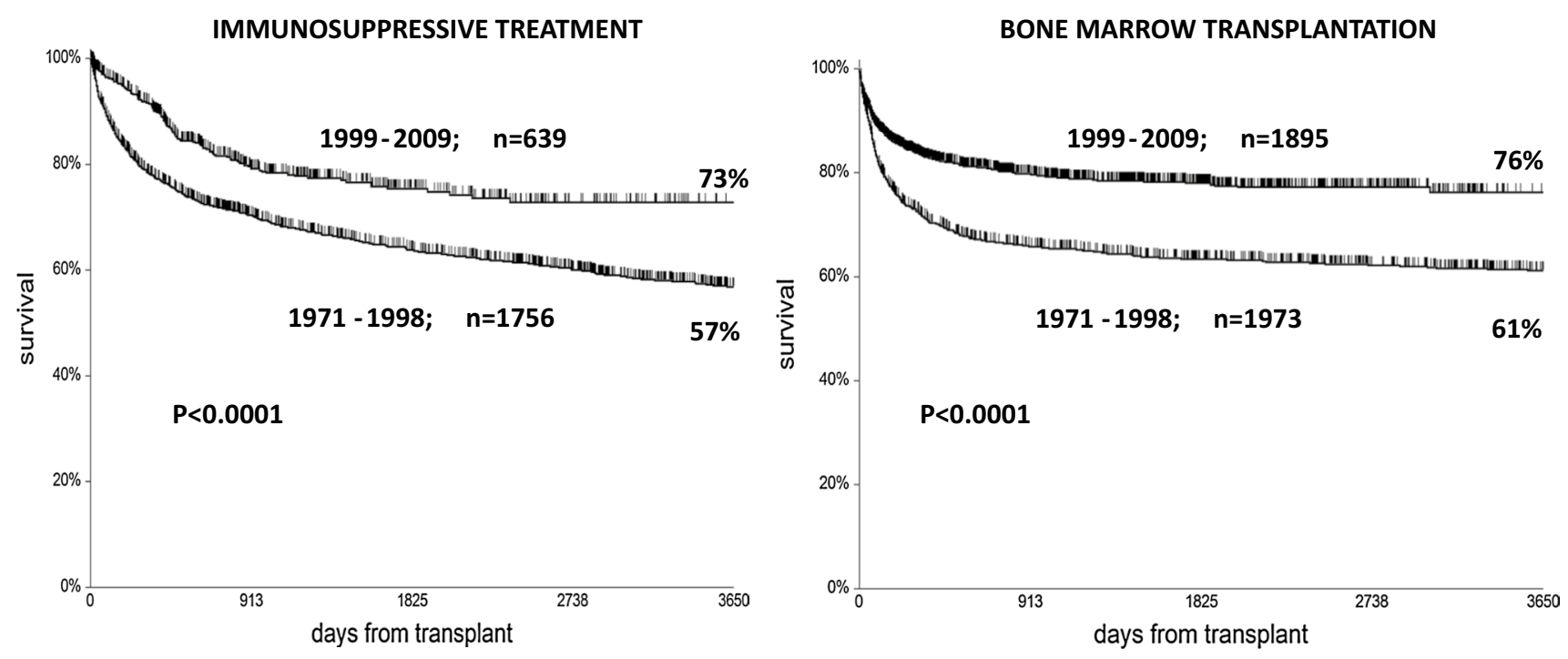

Fig. 1 Actuarial 10-year survival of patients receiving the first-line immunosuppressive treatment (IST) or bone marrow transplantation from an HLA identical sibling (BMT), stratified according to the year of treatment $(<1999 \geq)$ ). A significant improvement is seen for both groups 
These data suggest that early institution of EPAG may accelerate the rate and quality of hematopoietic recovery [21] and results of IST may further improve.

\section{Advances in bone marrow transplantation}

The outcome of patients treated with bone marrow transplantation (BMT) has improved with time, from 61 to $76 \%$ at 10 years (EBMT data base) [22-25] (Fig. 1). This figure includes transplants from HLA identical siblings (SIBS), HLA A, B, C, and DRB1-matched unrelated donors (UD), but also less well-matched UD, showing that overall there has been a very significant change in transplant protocols, and possibly also a better selection of UD, with high-resolution HLA typing. One should also consider that alternative donor transplants are performed in the vast majority of cases after having failed at least one course of IST: nevertheless, mortality in UD transplants has been halved, from 59 to $30 \%$ overall, before or after 1998 (EBMT database).

Therefore, we have witnessed a significant progress in survival for both patients receiving the first-line IST as well as the first-line BMT from HLA identical siblings. The question is how do these two forms of the first-line treatment compare in the last decade.

\section{BMT versus IST}

The choice between immunosuppressive therapy (IST) and bone marrow transplantation (BMT), for the treatment of patients with acquired severe aplastic anemia (SAA), is not always straight forward, and depend on variables, such as patients age, severity of the disease, and availability of a matched donor [24]. A study of the European Group for Blood and Marrow Transplantation
(EBMT), looked at failure free survival (FFS) (death, a second course of IST, marrow transplantation after failed IST or chronic GvHD), in patients receiving the firstline BMT from an HLA identical sibling or the first-line IST [25]. Failure free survival was superior in young patients $(<20$ years $)$ with a low neutrophil count $(<200 /$ $\mathrm{cmm}$ ) receiving BMT, whereas the opposite was true in older patents $(>40)$, with a higher neutrophil count $(>500 /$ $\mathrm{cmm}$ ). An intermediate group of patients (aged 21-40) with average neutrophil counts could be identified, with comparable FFS, irrespective of the first-line therapy, BMT, or IST. That study also showed that the advantage of BMT in young patients with low neutrophil counts, increased with time, due to the emergence of clonal disorders in IST-treated patients [26].

The question is: are these results still valid, in a more recent era, with the advances we have witnesses in both transplantation and IST? We have thus studied 6293 patients with SAA from the EBMT Registry of the SAA Working Party, to test the outcome of patients in 2 different time periods, with a cut off in year 1999.

\section{Patients}

Clinical characteristics are shown in Table 1. Patients receiving IST first-line, were younger in the most recent period $(\geq 1999)$, were treated earlier, at a median of 27 instead of 31 days, and had comparable severity of the disease, stratified as very severe (vSAA) $(<0.2$ neutrophils/10^9/L), severe (SAA) $\left(0.2-0-5 \times 10^{\wedge} 9 / \mathrm{L}\right)$, and non-severe $(\mathrm{nSAA})\left(>0.5 \times 10^{\wedge} 9 / \mathrm{l}\right)$. Patients receiving the first-line HLA identical BMT had more patients over 40 years in the most recent period $(p<0.001)$, comparable severity, and were treated somewhat later, with a median of 86 versus 66 days between diagnosis and transplant.
Table 1 Clinical

Characteristics of SAA patients treated with either IST or BMT first-line

\begin{tabular}{|c|c|c|c|c|c|c|}
\hline & \multicolumn{2}{|l|}{ IST } & \multirow[t]{2}{*}{$p$} & \multicolumn{2}{|l|}{ BMT } & \multirow[t]{2}{*}{$p$} \\
\hline & $<1999$ & $>1999$ & & $<1999$ & $>1999$ & \\
\hline Number of patients & 2131 & 802 & & 1598 & 1732 & \\
\hline \multicolumn{7}{|l|}{ Severity } \\
\hline vSAA & $41 \%$ & $41 \%$ & & $50 \%$ & $41 \%$ & \\
\hline SAA & $26 \%$ & $24 \%$ & & $27 \%$ & $25 \%$ & \\
\hline nSAA & $33 \%$ & $35 \%$ & 0.4 & $23 \%$ & $34 \%$ & 0.002 \\
\hline \multicolumn{7}{|l|}{ Age } \\
\hline $0-20$ & $40 \%$ & $45 \%$ & & $52 \%$ & $50 \%$ & \\
\hline $21-40$ & $35 \%$ & $30 \%$ & & $42 \%$ & $36 \%$ & \\
\hline$>40$ & $25 \%$ & $25 \%$ & 0.01 & $6 \%$ & $14 \%$ & $<0.0001$ \\
\hline Int Dx Tx (days) & 31 & 27 & 0.08 & 66 & 86 & $<0.0001$ \\
\hline Undergoing a BMT & $14 \%$ & $44 \%$ & 0.0000 & $100 \%$ & $100 \%$ & \\
\hline
\end{tabular}

vSAA very severe aplastic anemia, $S A A$ severe aplastic anemia, $n S A A$ non-severe aplastic anemia, Int $D x T x$ interval diagnosis transplant in days 

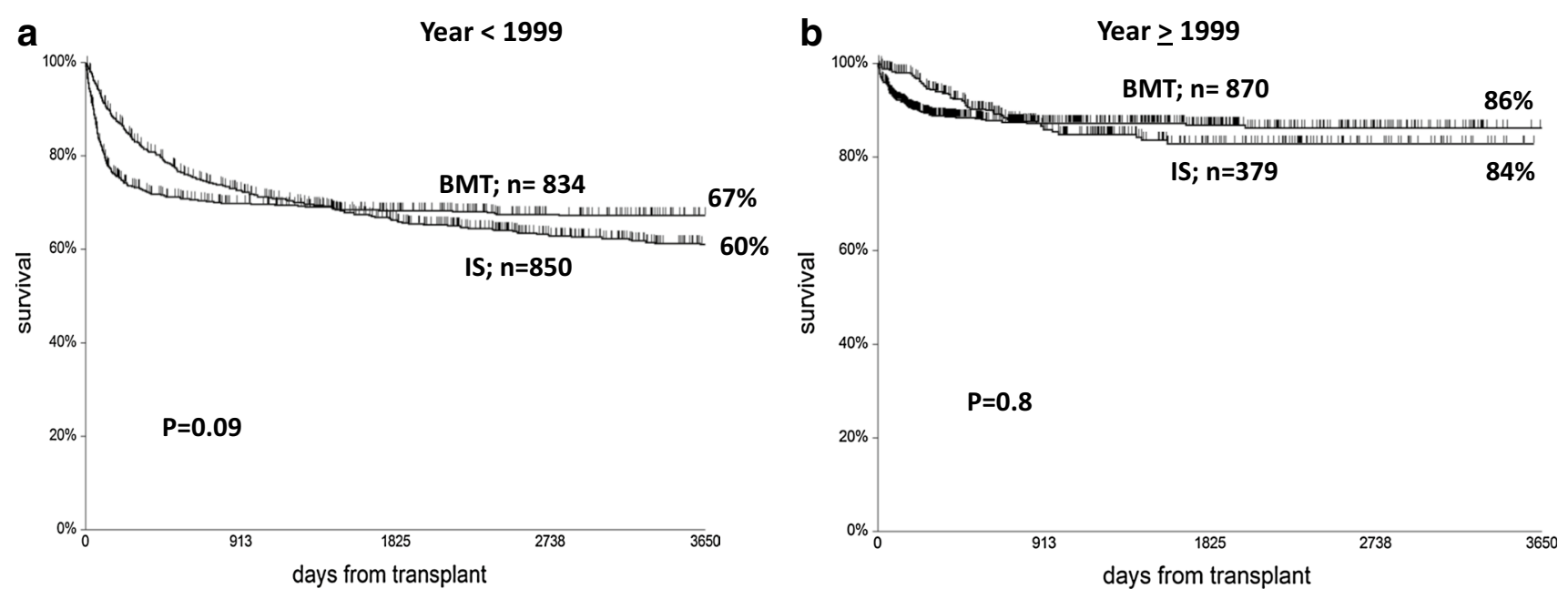

Fig. 2 Comparison of IST versus BMT in patients aged 1-20 years, before (Fig. 2a) or $\geq 1999$ (Fig. 2b)
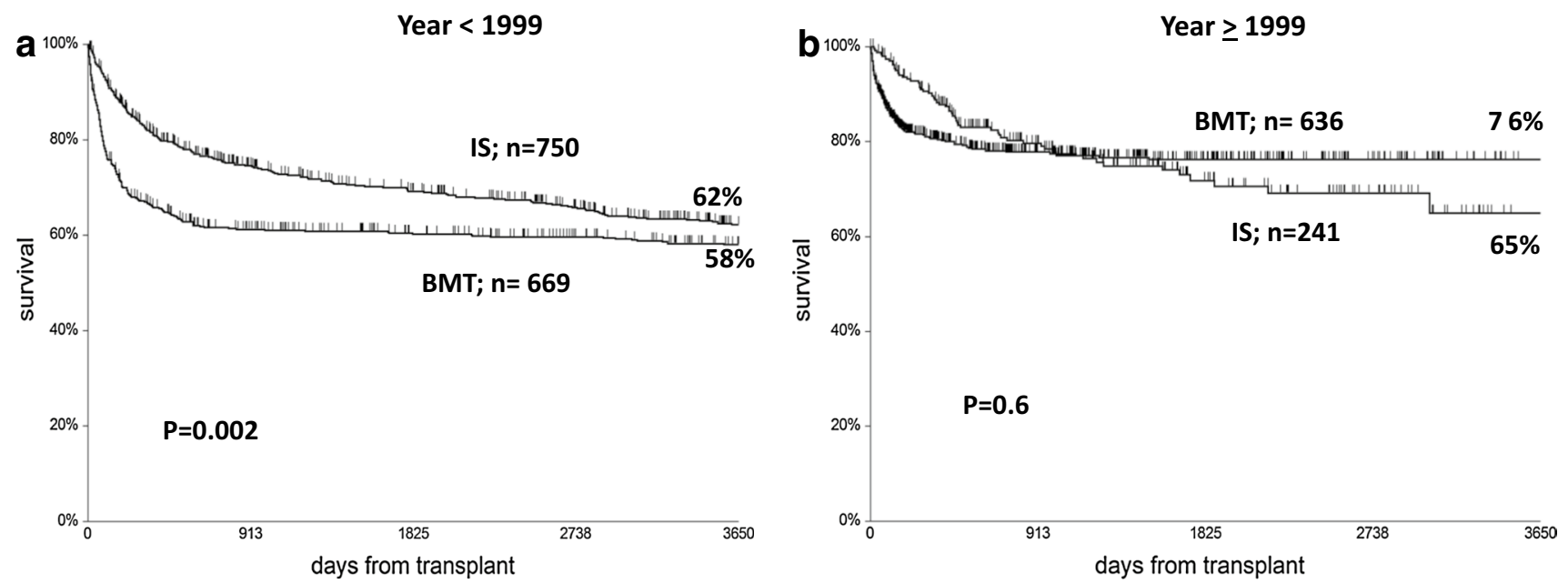

Fig. 3 Comparison of IST versus BMT in patients aged 21-40 years, before (Fig. 3a) or $\geq 1999$ (Fig. 3b). The advantage of IST is no longer seen in the last decade

\section{Univariate analysis}

Figure 2 depicts the actuarial 10-year survival for patients aged 1-20 years, treated first-line with either IST or BMT in the two time periods: both curves (Fig. 2a, b) show higher early mortality in the BMT group, which is compensated by higher late mortality in the IST group. The probability of being alive at 10 years in the period $\geq 1999$ is really identical in both groups.

Figure 3 outlines survival for patients aged 21-40 years in the 2 time periods. In the earlier period, there is a clear advantage for patients receiving IST at all time points (Fig. 3a). If one compares this results with the most recent decade (Fig. 3b), there is now no difference due to the significant improvement of the transplant group, from 58 to
$76 \%$, whereas the IST group has remained at the same survival (62 versus $65 \%$ ).

Figure 4 shows survival of the older patients aged over 40 years: no significant difference between IST and BMT before 1999 (Fig. 4a), but a significant survival advantage for IST over BMT in the most recent period (Fig. 4b).

\section{Multivariate analysis on survival}

A multivariate Cox on survival was run with the following variables: age (0-20, 21-40, $>40$ years); interval diagnosis transplant (Dx-Tx) ( $<100$ days; $\geq 100$ days), first-line treatment (IST, BMT), year of treatment $(>1999 ; \geq 1999)$; and severity of the disease $\left(<0.20 ; 0.21-0.5 ;>0.5 \times 10^{\wedge} 9 / \mathrm{L}\right.$ neutrophils). Results are shown in Table 2. 

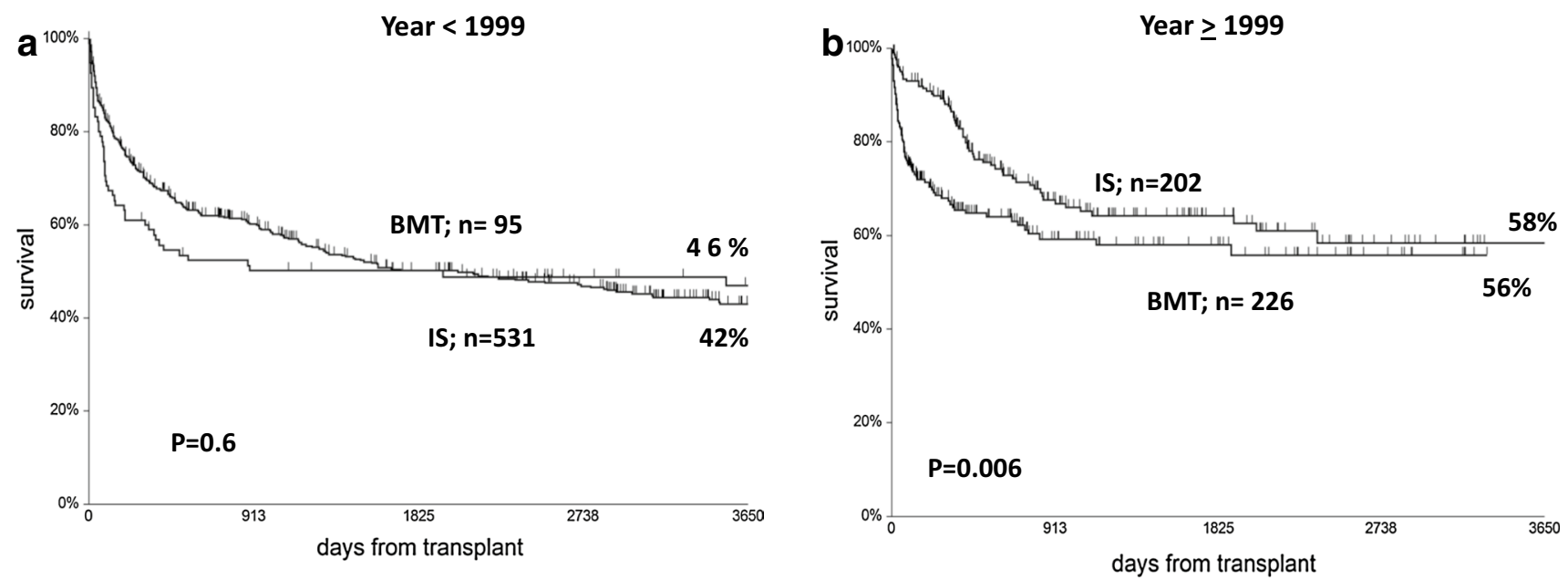

Fig. 4 Comparison of IST versus BMT in patients over 40 years of age, before (Fig. 4a) or $\geq 1999$ (Fig. 4b). There is a significant survival advantage for patients receiving the first-line IST in the last decade

Table 2 Multivariate Cox analysis

\begin{tabular}{|c|c|c|c|c|}
\hline & Baseline value & Compared value & $\mathrm{RR}$ & Confidence $p$ interval \\
\hline \multicolumn{5}{|l|}{ All patients } \\
\hline Year of treatment & $<1999$ & $\geq 1999$ & 0.69 & 0.0000 \\
\hline \multirow[t]{2}{*}{ Patients age (years) } & $0-20$ & $21-40$ & 1.18 & 0.02 \\
\hline & & $21-40$ & 2.11 & 0.0000 \\
\hline Interval Dx Tx (days) & $<100$ & $\geq 100$ & 1.56 & 0.0000 \\
\hline Treatment & IST & BMT & 0.90 & 0.11 \\
\hline \multirow[t]{2}{*}{ Severity of SAA } & vSAA & SAA & 0.69 & 0.0000 \\
\hline & & nSAA & 0.58 & 0.0000 \\
\hline \multicolumn{5}{|l|}{ Patients treated $<1999$} \\
\hline \multirow[t]{2}{*}{ Patients age (years) } & $0-20$ & $21-40$ & 1.09 & 0.2 \\
\hline & & $21-40$ & 2.00 & 0.0000 \\
\hline Interval Dx Tx (days) $<100$ & $\geq 100$ & 1.54 & 0.0000 & \\
\hline Treatment & IST & BMT & 0.90 & 0.18 \\
\hline \multirow[t]{2}{*}{ Severity of SAA } & vSAA & SAA & 0.67 & 0.0000 \\
\hline & & nSAA & 0.56 & 0.0000 \\
\hline \multicolumn{5}{|l|}{ Patients treated $\geq 1999$} \\
\hline \multirow[t]{2}{*}{ Patients age (years) } & $0-20$ & $21-40$ & 2.14 & 0.0003 \\
\hline & & $21-40$ & 3.12 & 0.0000 \\
\hline Interval Dx Tx (days) & $<100$ & $\geq 100$ & 1.77 & 0.002 \\
\hline Treatment & IST & BMT & 0.79 & 0.18 \\
\hline \multirow[t]{2}{*}{ Severity of SAA } & vSAA & SAA & 0.78 & 0.26 \\
\hline & & nSAA & 0.77 & 0.21 \\
\hline
\end{tabular}

When year of treatment was entered as a categorical variable (<1999; $\geq 1999)$, this proved highly significant, with a RR of death of 0.69 for patients treated in the most recent period. Other positive predictors of survival were a less severe disease, younger age, and early treatment ( $<100$ days). Similar results were seen when looking at patients treated before 1999. When testing whether things had changed in the most recent period ( $\geq 1999$ ), we found that severity of the disease was no longer significant, whereas patients' age and interval between diagnosis and treatment remained predictive. 


\section{Discussion}

The first finding of this study is a very significant improvement in survival, for patients with severe aplastic anemia treated $\geq 1999$, as compared to patients treated before 1999 (Fig. 1): it does not really matter if this has occurred because of improvement in BMT or IST, what matters are that both IST and BMT show a $15 \%$ improved survival. This is probably the most relevant result, since it shows improvement in a population-based analysis, and of course, this is important for the patient being admitted for the firstline therapy today.

The second finding is that more patients treated with the first-line IST, subsequently, received a BMT in the most recent period (44\%), as compared to patients treated with IST before $1999(14 \%)$. We do not believe this is because more patients failed IST beyond 1999: rather, there was probably a larger unrelated donor pool, in more recent years, and particularly improved results of UD grafts [27-30] must have encouraged hematologist to refer nonresponders for UD transplants. If receiving a transplant after IST is considered a failure, then failure free survival (FFS) of IST has decreased in the most recent period: indeed 10-year FFS was $40 \%$ before 1999 and it is $16 \%$ in the most recent period $(p<0.001)$. From another perspective, one could also say that the improved survival in patients receiving the first-line IST has derived from more patients being transplanted and improved outcome, especially for alternative donor grafts.

However, this brings us to the question: is survival or failure free survival more important? One should always think of counselling patients: if a first round of IST is not going to be significantly detrimental for a subsequent BMT, and this is probably true for UD grafts, then why not start with IST. This is relevant especially for patients over the age of 40: in this age group, Fig. 4b shows that starting with IST is possibly the best choice, since it results in significantly superior survival, as compared to patients receiving the first-line HLA identical sibling BMT. With the advent of eltrombopag, things may further change in the near future, in favor of IST first -line for patients over the age of 40 years.

The third finding is that age and interval between diagnosis and treatment remain very significant predictors of survival: older patients continue to do worse than younger patients, and this has not changed with time. This is rather extraordinary: we are now grafting patients over the age of 70 with acute leukemia or myelodysplastic syndromes, and we cannot figure out successful regimens for SAA patients over the age of 40 , for whom we are still facing a transplant mortality of $40 \%$. On the other hand, we can try and treat our patients as soon as possible, since it seems crucial to intervene within 100 days from diagnosis, whatever treatment one chooses, and for the older patients, IST remains the standard first-line.

Finally, severity of the disease: patients with a very low count $\left(<0.2 \times 10^{\wedge} 9 / \mathrm{L}\right.$ neutrophils $)$ or very severe aplastic anemia have always done poorly as compared to patients with a higher count: this seems to be less true currently, again possibly due to the fact that more patients are getting transplanted.

In conclusions, this study shows very encouraging outcome data in a large cohort of patients with SAA. Results are gradually improving and current advances, such as the use of eltrombopag in IST, and better platforms for alternative donor transplants, including better donor selection, are paving the way for further improvement in patients treated beyond 2010 .

\section{References}

1. Young NS, Calado RT, Scheinberg P. Current concepts in the pathophysiology and treatment of aplastic anemia. Blood. 2006;108(8):2509-19.

2. Vulliamy T, Marrone A, Goldman F, Dearlove A, Bessler M, Mason PJ, Dokal I. The RNA component of telomerase is mutated in autosomal dominant dyskeratosis congenita. Nature. 2001;413(6854):432-5.

3. Townsley DM, Dumitriu B, Young NS. Bone marrow failure and the telomeropathies. Blood. 2014;124(18):2775-83.

4. Calado RT, Yewdell WT, Wilkerson KL, Regal JA, Kajigaya S, Stratakis CA, Young NS. Sex hormones, acting on the TERT gene, increase telomerase activity in human primary hematopoietic cells. Blood. 2009;114(11):2236-43.

5. Najean Y, Haguenauer O. Long-term (5 to 20 years) evolution of nongrafted aplastic anemias. The Cooperative Group for the Study of Aplastic and Refractory Anemias. Blood. 1990;76(11):2222-8 (PubMed PMID: 2257296).

6. Narita A, Muramatsu H, Sekiya Y, Okuno Y, Sakaguchi H, Nishio N, Yoshida N, Wang X, Xu Y, Kawashima N, Doisaki S, Hama A, Takahashi Y, Kudo K, Moritake H, Kobayashi M, Kobayashi R, Ito E, Yabe H, Ohga S, Ohara A, Kojima S, Japan Childhood Aplastic Anemia Study Group. Paroxysmal nocturnal hemoglobinuria and telomere length predicts response to immunosuppressive therapy in pediatric aplastic anemia. Haematologica. 2015;100(12):1546-52.

7. Yoshizato T, Dumitriu B, Hosokawa K, Makishima H, Yoshida K, Townsley D, Sato-Otsubo A, Sato Y, Liu D, Suzuki H, Wu CO, Shiraishi Y, Clemente MJ, Kataoka K, Shiozawa Y, Okuno Y, Chiba K, Tanaka H, Nagata Y, Katagiri T, Kon A, Sanada M, Scheinberg P, Miyano S, Maciejewski JP, Nakao S, Young NS, Ogawa S. Somatic mutations and clonal hematopoiesis in aplastic anemia. N Engl J Med. 2015;373(1):35-47.

8. Frickhofen N, Kaltwasser JP, Schrezenmeier H, et al. Treatment of aplastic anemia with antilymphocyte globulin and methylprednisolone with or without cyclosporine: the German Aplastic Anemia Study Group. N Engl J Med. 1991;324(19):1297-304.

9. Rosenfeld SJ, Kimball J, Vining D, Young NS. Intensive immunosuppression with antithymocyte globulin and cyclosporine as treatment for severe acquired aplastic anemia. Blood. 1995;85(11):3058-65. 
10. Führer M, Burdach S, Ebell W, et al. Relapse and clonal disease in children with aplastic anemia (AA) after immunosuppressive therapy (IST): the SAA 94 experience. German/Austrian Pediatric Aplastic Anemia Working Group. Klin Padiatr. 1998;210(4):173-9.

11. Kojima S, Hibi S, Kosaka Y, et al. Immunosuppressive therapy using antithymocyte globulin, cyclosporine, and danazol with or without human granulocyte colony-stimulating factor in children with acquired aplastic anemia. Blood. 2000;96(6):2049-54.

12. Zeigler FC, de Sauvage F, Widmer HR, Keller GA, Donahue C, Schreiber RD, Malloy B, Hass P, Eaton D, Matthews W. In vitro megakaryocytopoietic and thrombopoietic activity of c-mpl ligand (TPO) on purified murine hematopoietic stem cells. Blood. 1994;84(12):4045-52.

13. Kimura S, Roberts AW, Metcalf D, Alexander WS. Hematopoietic stem cell deficiencies in mice lacking c-Mpl, the receptor for thrombopoietin. Proc Natl Acad Sci USA. 1998;95(3):1195-200.

14. Qian H, Buza-Vidas N, Hyland CD, Jensen CT, Antonchuk J, Månsson R, Thoren LA, Ekblom M, Alexander WS, Jacobsen SE. Critical role of thrombopoietin in maintaining adult quiescent hematopoietic stem cells. Cell Stem Cell. 2007;1(6):671-84.

15. Yoshihara H, Arai F, Hosokawa K, Hagiwara T, Takubo K, Nakamura Y, Gomei Y, Iwasaki H, Matsuoka S, Miyamoto K, Miyazaki H, Takahashi T, Suda T. Thrombopoietin/MPL signaling regulates hematopoietic stem cell quiescence and interaction with the osteoblastic niche. Cell Stem Cell. 2007;1(6):685-97.

16. Geddis AE. Congenital amegakaryocytic thrombocytopenia. Pediatr Blood Cancer. 2011;57(2):199-203.

17. Walne AJ, Dokal A, Plagnol V, Beswick R, Kirwan M, de la Fuente J, Vulliamy T, Dokal I. Exome sequencing identifies MPL as a causative gene in familial aplastic anemia. Haematologica. 2012;97(4):524-8.

18. Olnes MJ, Scheinberg P, Calvo KR, Desmond R, Tang Y, Dumitriu B, Parikh AR, Soto S, Biancotto A, Feng X, Lozier J, Wu CO, Young NS, Dunbar CE. Eltrombopag and improved hematopoiesis in refractory aplastic anemia. N Engl J Med. 2012;367(1):11-9.

19. Desmond R, Townsley DM, Dumitriu B, Olnes MJ, Scheinberg P, Bevans M, Parikh AR, Broder K, Calvo KR, Wu CO, Young NS, Dunbar CE. Eltrombopag restores trilineage hematopoiesis in refractory severe aplastic anemia that can be sustained on discontinuation of drug. Blood. 2014;123(12):1818-25.

20. Will B, Kawahara M, Luciano JP, Bruns I, Parekh S, EricksonMiller CL, Aivado MA, Verma A, Steidl U. Effect of the nonpeptide thrombopoietin receptor agonist Eltrombopag on bone marrow cells from patients with acute myeloid leukemia and myelodysplastic syndrome. Blood. 2009;114(18):3899-908.

21. Townsley DM, Dumitriu B, Scheinberg P, Desmond R, Feng X, Rios O, Weinstein B, Valdez J, Winkler T, Desierto M, Leuva H, Wu C, Calvo KR, Larochelle A, Dunbar CE, Young NS. LBA-2 eltrombopag added to standard immunosuppression for aplastic anemia accelerates count recovery and increases response rates. Blood. 2015;126:LBA-2.

22. Storb R, Erzioni R, Anasetti C, Appelbaum FR, Buckner CD, Besinger W, Bryant E, Clift R, Deeg HJ, Doney K, Flowers M,
Hansen J, Martin P, Pepe M, Sale G, Sanders J, Singer J, Sullivan KM, Thomas ED, Witerspoon RP. Cyclophosphamide combined with antithymocyte globulin in preparation for allogeneic marrow transplants in patients with aplastic anemia. Blood. 1994;84:941-9.

23. Marsh JC, Gupta V, Lim Z, Ho AY, Ireland R, Hayden J, Potter V, Koh MB, Islam MS, Russell N, Marks DI, Mufti GJ, Pagliuca A. Alemtuzumab with fludarabine and cyclophosphamide reduces chronic graft versus host disease after allogeneic stem cell transplantation for acquired aplastic anemia. Blood. 2011;118(8):2351-7.

24. Locasciulli Anna, Oneto Rosi, Bacigalupo Andrea, Socié Gerard, Korthof Elisabeth, Bekassy Albert, Schrezenmeier Hubert, Passweg Jakob, Monika Führer on the behalf of the Severe Aplastic Anemia Working Party of the European Group for Blood and Marrow Transplantation (SAA-WP, BMT). Outcome of patients with acquired aplastic anemia given first line bone marrow transplantation or immunosuppressive treatment in the last decade: a report from the European Group for Blood and Marrow Transplantation (EBMT). Haematologica. 2007;92(1):11-8.

25. Bacigalupo A, Brand R, Oneto R, Bruno B, Sociè G, Passweg J, Locasciulli A, van Lint MT, Tichelli A, McCann S, Marsh J, Ljungman P, Hows J, Marin P, Schrezenmeier H. Treatment of acquired severe aplastic anemia: bone marrow transplantation compared with immunosuppressive therapy-The European Group for Blood and Marrow Transplantation Experience. Semin Hematol. 2000;37:69-80.

26. Socié G, Rosenfeld S, Frickhofen N, Gluckman E, Tichelli A. Late clonal diseases of treated aplastic anemia. Semin Hematol. 2000;37(1):91-101.

27. Bacigalupo A, Socie' G, Lanino E, Prete A, Locatelli F, Locasciulli A, Cesaro S, Shimoni A, Marsh J, Brune M, Van Lint MT, Oneto R, Passweg J, Severe Aplastic Anemia Working Party of the European Group for Blood and Marrow Transplantation. Fludarabine, cyclophosphamide, antithymocyte globulin, with or without low dose total body irradiation, for alternative donor transplants, in acquired severe aplastic anemia: a retrospective study from the EBMT-SAA working party. Haematologica. 2010;95(6):976-82.

28. Kojima S, Matsuyama T, Kato S, et al. Outcome of 154 patients with severe aplastic anemia who received transplants from unrelated donors: the Japan Marrow Donor Program. Blood. 2002;100:799-803.

29. Okuda S, Terasako K, Oshima K, Sato M, Nakasone H, Kako S, Yamazaki R, Tanaka Y, Tanihara A, Higuchi T, Nishida J, Kanda Y. Fludarabine, cyclophosphamide, anti-thymocyteglobulin, and low-dose total body irradiation conditioning enables 1-HLAlocus-mismatched hematopoietic stem cell transplantation for very severe aplastic anemia without affecting ovarian function. Am J Hematol. 2009;84(3):167-9.

30. Samarasinghe S, Steward C, Hiwarkar P, Saif MA, Hough R, Webb D, et al. Excellent outcome of matched unrelated donor transplantation in paediatric aplastic anaemia following failure with immunosuppressive therapy: a United Kingdom multicentre retrospective experience. Br J Haematol. 2012;157(3):339-46. 